\title{
Influence Of Addition Of Rice Husk Charcoal On Aggregate Against Strong Press Concrete \\ Subandi ${ }^{1}$, Chandra Kusuma ${ }^{2}$, \\ 1 \# Civil engineering students, Universitas Muhammadiyah Kalimantan Timur. Jalan Juanda no. 15, Samarinda, Indonesia
}

\begin{abstract}
The development of manufacture of concrete from the day kehari more advanced, many ways that are guaranteed to add a kekuaan concrete, either with chemicals or natural substances derived from waste, such as from the research using rice husk added that made into charcoal that are mixed into the concrete as much as $10 \%$ of the weight of cement, was able to increase the strength of the concrete. At the age of 28 days of testing concrete strength obtained concrete amounted to $23.5 \mathrm{Mpa}$ from the quality plan of $20 \mathrm{MPa}$.
\end{abstract}

\section{BAB I}

\section{PENDAHULAN}

\subsection{Latar Belakang}

Beton salah satu bahan konstruksi yang saat ini mengalami kemajuan yang sangat pesat. Hal ini tidak lepas dari tuntutan dan kebutuhan masyarakat terhadap infrastruktur yang semakin maju. Beton merupakan salah satu pilihan sebagai bahan dasar struktur dalam konstruksi bangunan. Pada umumnya beton tersusun dari semen, agregat halus, agregat kasar dan air. Namun seiring dengan perkembangan ilmu pengetahuan dan teknologi, bahan penyusun beton juga ikut berubah. Salah satu contohnya adalah dengan dimasukkannya bahan tambah ataupun bahan pengganti dalam beton. Pemanfaatan Arang Sekam Padi untuk campuran beton merupakan salah satu langkah untuk mengurangi permasalahan Sekam Padi yang sangat banyak. Sekam Padi merupakan limbah dari hasil pengolahan beras, hal ini seringkali menimbulkan pencemaran lingkungan dan folusi udara. Arang Sekam Padi tersebut mempunyai berat yang ringan. 
Berdasarkan data dari kementan pada tahun 2016 jumlah padi yang dihasilkan sebanyak \pm 7 Juta ton, Arang Sekam Padi mempunyai berat 11 $13 \%$ dari berat beras maka sekam padi menghasilkan \pm 700 ribu ton pada tahun 2016 dimana 5\% nya digunakan sebagai media tanam dan abu gosok selebihnya dibuang dan dibakar.

Arang Sekam Padi yang kita gunakan merupakan limbah pengolahan beras Padi yang 95 \% nya tidak digunakan, Komposisi kimia pada Sekam padi menurut DTC - IPB :

1. Karbon (zat arang) : $1,33 \%$

2. Hidrogen : $1,54 \%$

3. Oksigen : $33,64 \%$

4. Silika $16,98 \%$

Seperti kita ketahui silika merupakan salah satu bahan baku pembuatan semen portlan.

\subsection{Rumusan Masalah}

Berdasarkan latar belakang masalah yang telah diuraikan diatas, maka rumusan masalah dalam penelitian ini sebagai berikut :

1. Bagaimana pengaruh Arang Sekam Padi sebagai bahan tambahan terhadap kuat tekan beton?

\subsection{Tujuan}

Adapun tujuan penelitian ini adalah :

1. Untuk mengetahui nilai kuat tekan beton pada umur 14 hari dan 28 hari sebagai bahan tambah campuran beton.

\subsection{Manfaat Penilitian}

Adapun manfaat dari studi penelitian ini untuk:

1. Memperoleh ilmu pengetahuan tentang material bahan bangunan 
2. Untuk membantu memanfaatkan limbah Arang Sekam Padi agar tidak mencemari lingkungan dan menggangu kesehatan masyarakat sekitar.

3. Sebagai alternatif bahan bangunan yang ramah lingkungan murah, kuat, dan ringan.

\section{BAB II}

\section{TINJAUAN PUSTAKA}

\subsection{Penelitian Terdahulu}

\subsection{Beton}

Murdock dan Brook (1986) secara jelas menyebutkan bahwa beton adalah suatu bahan bangunan dan bahan konstruksi, yang sifat-sifatnya dapat ditentukan lebih dahulu dengan mengadakan perencanaan dan pengawasan yang teliti terhadap bahan-bahan yang dipilih. Bahan-bahan pilihan itu adalah ikatan keras, yang ditimbulkan oleh reaksi kimia antar semen dan air, serta agregat, dimana semen yang mengeras itu ber-adhesi dengan baik maupun kurang baik.

Penggunaan agregat dari kayu ulin dan arang sekam padi dalam membuat beton ringan pernah dilakukan dan menghasilkan beton ringan struktural 22 $\mathrm{MPa}[1]$ 
Agregat boleh berupa kerikil, batu pecah, sisa bahan mentah tambang, agregat ringan buatan, pasir, atau bahan sejenis lainnya. Kekuatan, keawetan, dan sifat beton tergantung dari nilai perbandingan bahan dasar beton, sifat bahan dasarnya, cara pengadukan, pengerjaan, penuangan, pemadatan serta perawatan selama proses pengerasan. Untuk membuat beton yang baik maka harus diperhitungkan cara mendapatkan adukan beton segar yang baik dan beton keras yang dihasilkan juga baik. Pencapaian kuat beton yang baik perlu diperhatikan kepadatan dan kekerasan massanya karena umumnya semakin keras dan padat massa penyusunnya makin tinggi kekuatan dan durability-nya.

Agar dihasilkan kuat tekan beton yang sesuai dengan rencana diperlukan mix design untuk menentukan jumlah masing-masing bahan penyusun yang dibutuhkan. Disamping itu, adukan beton harus diusahakan dalam kondisi yang benar-benar homogen dengan kelecakan tertentu agar tidak terjadi pemisahan. Selain perbandingan bahan susunnya, kekuatan beton ditentukan oleh padat tidaknya campuran bahan penyusun beton tersebut. Semakin kecil rongga yang dihasilkan dalam campuran beton, maka semakin tinggi kuat desak beton yang dihasilkan.

\subsubsection{Bahan Penyusun Beton}

Bahan penyusun beton terdiri dari semen, agregat halus, agregat kasar dan air. Dalam penelitian kali ini kami juga menambahkan limbah Arang Sekam Padi sebagai bahan tambah beton.

\subsubsection{Porland Semen}

Semen portland merupakan semen hidrolis yang dihasilkan dengan cara menggiling terak semen potland terutama yang terdiri atas kalsium silikat yang bersifat hidrolis dan digiling bersama - sama dengan bahan tambahan berupa satu atau lebih bentuk kristal senyawa kalsium sulfat dan boleh ditambahkan dengan bahan lain [2] 


\subsubsection{Agregat}

Agregat dibedakan menjadi 2 jenis yaitu agregat halus dan agregat kasar cara membedakannya berdasarkan pada ukuran butiran butirannya :

\section{Agregat halus}

Agregat halus adalah pasir alam sebagai hasil disintregasi alami batuan ataupun pasir yang dihasilkan oleh industri pemecah batu dan mempunyai ukuran butir lebih kecil dari 3/16 inci atau $5 \mathrm{~mm}$ (lolos saringan no. 4).

\section{Agregat kasar}

Menurut [3], agregat kasar adalah kerikil sebagai hasil disintegrasi alami dari batuan atau berupa batu pecah yang diperoleh dari industri pemecah batu dan mempunyai ukuran butir antara 4,75 mm (No.4) sampai $40 \mathrm{~mm}$ (No. 11/2 inci).

\subsubsection{Air}

Air diperlukan untuk bereaksi dengan semen, serta untuk dijadikan bahan pelumas antar butir - butir agregat agar dapat mudah dikerjakan dan dipadatkan. Untuk bereaksi dengan semen, air yang diperlukan sekitar $25 \%$ dari berat semen, namun dalam kenyataannya nilai air semen yang dipakai lebih kurang 0,35.

\subsection{Arang Sekam Padi}

\subsubsection{Pengertian}

Material dasar Arang Sekam Padi merupakan limbah dari penggilingan padi yang dibakar dan menjadi arang yang membentuk unsur kimia menurut DTC - IPB :

1. Karbon (zat arang) : $1,33 \%$

2. Hidrogen : $1,54 \%$ 
3. Oksigen : $33,64 \%$

4. Silika $16,98 \%$

\subsubsection{Alasan Memilih Bahan Tambah Arang Sekam Padi}

Penggunaan Arang Sekam Padi sebagai bahan tambah beton selain bertujuan memanfaatkan Arang Sekam Padi, juga untuk mencari bahan tambah alternatif yang apabila ditambahkan dalam adukan beton menghasilkan beton yang mempunyai nilai lebih baik dari beton biasa. Selain itu, menambahkan bahan tambah Arang Sekam Padi pada beton juga bertujuan untuk menguji kuat tekan terhadap beton tersebut.

BAB III

\section{METODELOGI}

\subsection{Lokasi Penelitian}

Pelaksanaan penelitian yang meliputi pemeriksaan serta pengujian bahan, pembuatan benda uji, perawatan dan pengujian beton dilakukan di Laboratorium Teknologi Beton, Fakultas Teknik, Jurusan Sipil Universitas Muhammadiyah Kalimantan Timur.

\subsection{Rancangan Penelitian}

\subsubsection{Benda Uji}

Pada penelitian ini benda uji yang digunakan adalah benda uji silinder dengan diameter ukuran $15 \mathrm{~cm}$ dan tinggi $30 \mathrm{~cm}$ [4]

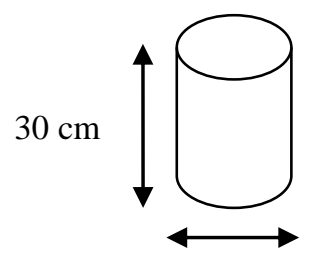

$15 \mathrm{~cm}$

Gambar 3.1 Benda uji silinder 


\subsubsection{Rancangan Benda Uji}

Penelitian menggunakan campuran bahan tambah dengan limbah Arang Sekam Padi Arang Sekam Padi bening dengan bahan PP pada benda uji silinder ukuran diameter 7,5 cm x $15 \mathrm{~cm}$ dan dibuat variasi persentase sebanyak 0,2\% dari jumlah semen.

\subsection{Alur Penelitian}

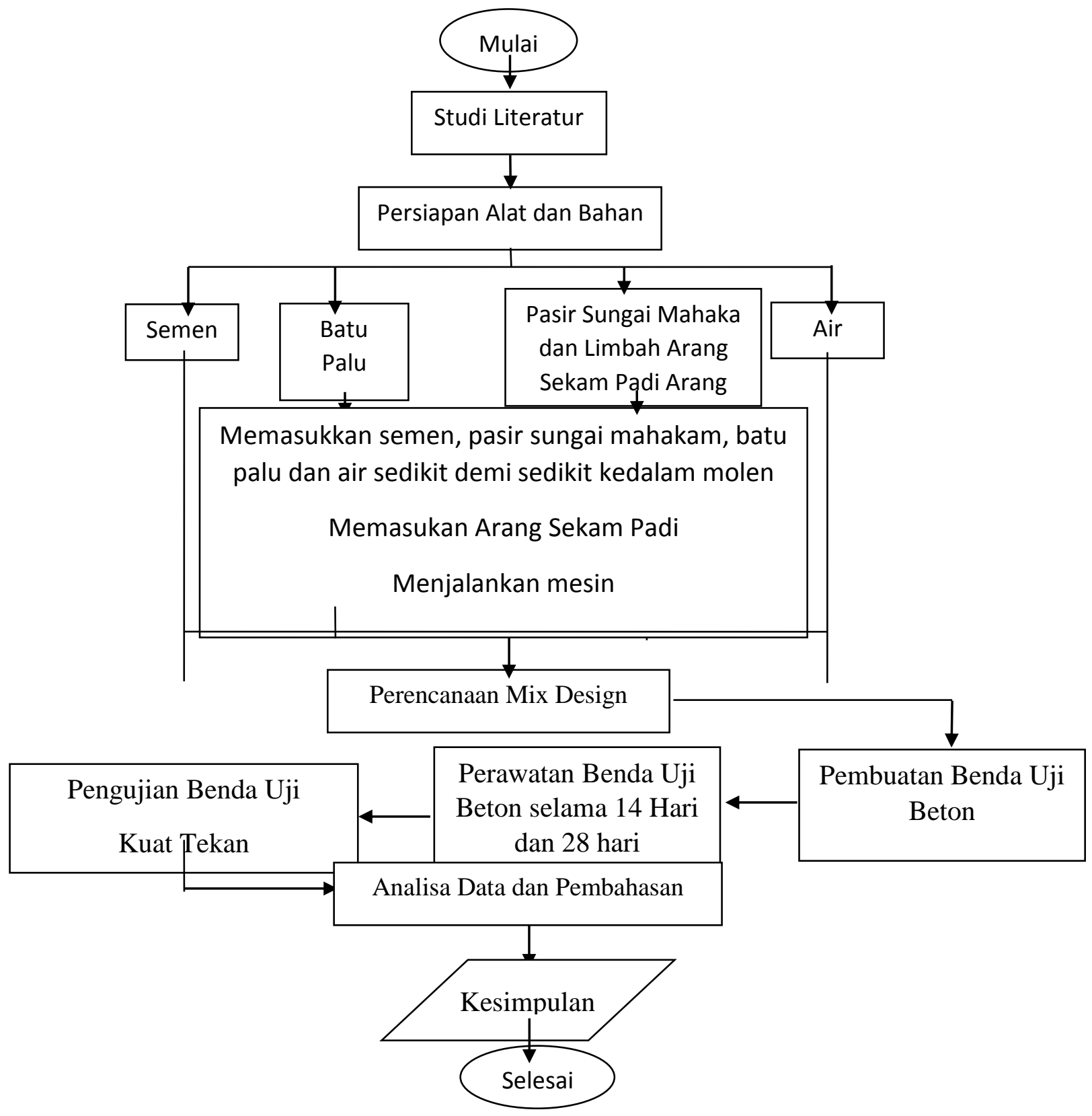




\subsection{Alat dan Bahan}

\subsubsection{Alat Penelitian}

1. Mesin molen atau mixer semen berfungsi untuk alat pengaduk campuran semen.

2. Timbangan berfungsi untuk mengukur massa suatu benda

3. Wadah

4. Sekop/cangkul

5. Ember

6. Sedok spesi

7. Kerucut abrams dan tongkat baja perojok untuk mengukur nilai slump

8. Cetakan benda uji silinder diameter $7,5 \mathrm{~cm}$ dan $15 \mathrm{~cm}$

9. Bak perendam benda uji untuk perawatan benda uji

10. Peralatan pembuka cetakan

11. Compression testhing

\subsubsection{Bahan Uji}

1. Semen yang dipergunakan adalah semen porland tipe 1

2. Batu Palu Tenggarong.

3. Pasir yang dipergunakan yaitu yang berasal dari pasir sungai Mahakam atau Tenggarong.

4. Limbah Arang Sekam Padi .

5. Air yang dipergunakan ialah air bersih dari jaringan laboratorium Universitas Muhammadiyah Kalimantan Timur

\subsection{Perhitungan Mix Design}

Maksud dari mix design (perancangan) adalah untuk menentukan perbandingan campuran bahan untuk mendapatkan beton dengan kuat tekan rata rata sesuai yang ditargetkan pada umur 28 hari. Perbandingan campuran bahan bahan beton harus dipilih untuk mendapatkan beton yang paling ekonomis, 
sehingga dengan menggunakan bahan - bahan tersedia akan mempunyai kekuatan seperti yang diinginkan. Setelah melakukan pengujian karakteristik bahan baku penelitian, maka dilakuakn perhitungan rencana campuran beton. Dalam penelitian ini perhitungan campuran diperuntukan untuk beton normal dengan bahan dasar pembentuk beton yaitu semen Portland tipe 1, agregat halus, agregat kasar dan air.

Rencana Mix Design

Untuk $1 m^{3}$ Beton (berat betonnya $2375 \mathrm{~kg}$ ) dibutuhkan :

- Air = 179 liter

- Semen $\quad=351 \mathrm{~kg}$

- Pasir = $729 \mathrm{~kg}$

- Batu Palu $\quad=1116 \mathrm{~kg}$

Untuk 1 adukan dibutuhkan ( 6 buah silinder) :

- Berat beton =0,0382 $\times 2375=90,725 \mathrm{~kg}$

- Air $\quad=0,0382 \times 225=8,595$ liter (pembulatan 9 liter)

- Semen $\quad=0,0382 \times 604,8=23,10336 \mathrm{~kg}$ (pembuatan $24 \mathrm{~kg}$ )

- Pasir =0,0382 x 816,31=31,183 $\mathrm{kg}($ pembulatan $32 \mathrm{~kg}$ )

- Batu Palu $=0,0382 \times 723,90=27,652 \mathrm{~kg}$ (pembulatan $28 \mathrm{~kg}$ )

\subsection{Pembuatan Benda Uji Beton}

Setelah pengujian material dan perhitungan campuran dilakukan, maka benda uji dapat dibuat. Umumnya dalam pembuatan adukan dan benda uji beton ditempuh 3 tahapan, yaitu tahap pengadukan, tahap pencetakan dan tahap perawatan.

\subsubsection{Tahap Pengadukan}

1. Bahan baku disiapkan dan ditimbang sesuai proposi berat yang telah ditentukan. 
2. Agregat kasar, agregat halus dan limbah Arang Sekam Padi bersama - sama dimasukkan seluruhnya ke dalam mesin pengaduk, kemudian nyalakan mesin. Ketiga bahan tersebut diaduk hingga merata.

3. Mesin dimatikan, lalu dimasukkan semen dan $2 / 3$ dari bagian air dan mesin dinyalakan kembali.

4. Setelah 2 menit, mesin dimatikan dan material yang berada didasar mesin serta yang belum teraduk, diaduk kembali dengan menggunakan sendok semen.

5. Setelah itu mesin dijalankan kembali selama 2 menit sambil menuangkan sisa air.

6. Setelah semua material campuran dimasukkan kedalam mesin, aduklah beton selama 3 menit. Hentikan mesin, tutup mesin dan proses pengadukan telah selesai.

\subsubsection{Tahap Pencetakkan Benda Uji}

1. Cetakan disiapkan, sebelumnya diberi pelumas terlebih dahulu pada bagian dinding dalam cetakan agar memudahkan pada waktu melepaskan benda uji dari cetakan.

2. Adukan beton dimasukkan kecetakan dalam 3 lapisan. Dimana setiap lapisan terdiri dari masukkan beton $1 / 3$ cetakan lalu ditusuk 25 kali, untuk meminimalisir rongga udara dalam beton, sehingga beton tidak keropos.

3. Setelah penuh, cetakan digoyang - goyang juga tujuan agar rongga udara yang terbentuk lebih sedikit.

4. Meratakan adonan dalam cetakan dan didiamkan pada udara terbuka selama 24 jam hingga beton mengeras.

\subsubsection{Tahap Perawatan (curing)}

1. Perawatan dilakukan dengan cara merendam benda uji yang telah mengeras dalam bak air selama batas umur yang ditentukan untuk dilakukan pengujian. 
2. Pada benda uji diberi kode sesuai dengan persentase bahan yang digunakan. Hal ini dimaksudkan untuk memudahkan identifikasi, sehingga tidak menyulitkan pada saat dilakukan penujian.

3. Suhu rata - rata pada bak perendaman benda uji tersebut harus berkisar antara $25-27$ derajat celcius.

\subsection{Metode Pengujian Beton}

Untuk memenuhi tujuan penelitian, maka dilakukan pengujian terhadap kuat tekan beton. Pengujian - pengujian tersebut dilakukan pada umur 14 hari dan 28 hari.

\subsubsection{Uji Kuat Tekan Beton}

Uji kuat tekan dilakukan setelah benda uji dilakuakn perawatan sesuai umur perawatan yang direncanakan, dengan langkah - langkah pengujian sebagai berikut :

a. Letakkan benda uji pada mesin tekan secara simetris.

b. Jalankan mesin tekan dengan penambahan beban 2 sampai $4 \mathrm{~kg} / \mathrm{cm}^{2}$ per-detik.

c. Lakukan pembebanan sampai benda uji menjadi hancur.

d. Catatlah beban maksimum yang terjadi selama pemeriksaan benda uji.

e. Hitunglah kuat tekan beton, yaitu besarnya beban persatuan luas.

\section{BAB IV}

\section{PEMBAHASAN}

\subsection{Hasil uji beton}

Penelitian ini dilakukan di laboratorium dinas pekerjaan umum penataan ruang dan perumahan rakyat UPTD pemeliharaan infrastruktur pekerjaan umum wilayah II dengan menggunakan agregat Arang Sekam Padi jenis PP (Polythelene) dengan parameter uji kuat tekan beton. Bahan beton berupa agregat Arang Sekam Padi yang berbahan semen, batu palu, pasir, dan air dicampur sesuai ukuran standar 
masing-masing yang ditentukan. Dari bahan-bahan tersebut kemudian mengukur massanya menggunakan timbangan.

\subsection{1 slump test}

Uji slump adalah suatu uji empiris atau metode yang digunakan untuk menentukan konsistensi atau kekuatan dari campuran beton segar untuk menentukan tingkat workabilitynya. Dalam suatu adukan atau campuran beton, kadar air sangat diperhatikan karena menentukan tingkat workbility nya atau tidak. Campuran beton yang terlalu cair akan menyebabkan mutu beton rendah dan lama mengering. Sedangkan campuran beton yang terlalu kering menyebabkan adukan tidak merata dan sulit untuk dicetak.

Adapun bahan, alat, dan tahapan pengujian slump test sebagai berikut :

Bahan

1. Beton segar yang diambil secara acak agar dapat mewakili beton secaara keseluruhan.

Alat :

1. Kerucut abrams sebagai cetakan slump. Diameter bawah $20 \mathrm{~cm}$, diameter atas $10 \mathrm{~cm}$, tinggi $30 \mathrm{~cm}$.

2. Batang besi penusuk. Diameter $16 \mathrm{~mm}$, panjang $60 \mathrm{~cm}$.

3. Sendok adukan

4. Pita ukur

Tahapan uji slump

1. Letakan cetakan diatas plat 
2. Isi 1/3 cetakan dengan beton segar, padatkan dengan batang besi penusuk. Lapisan ini penusukan bagian tepi dilakukan dengan besi dimiringkan sesuai dengan dinding cetakan pastikan menyentuh dasar. Lakukan 25 kali tusukan.

3. Isi $1 / 3$ bagian berikutnya (menjadi $2 / 3$ ) dengan hal yang sama sebanyak 25 kali tusukan. Pastikan besi menyentuh lapisan pertama.

4. Isi 1/3 akhir seperti tahapan no 4.

5. Setelah selesai dipadatkan, ratakan permukaa benda uji.

6. Cetakan diangkat tegak lurus ke atas.

7. Ukur nilai slump.

Perhitungan nilai slump

Nilai slump = tiggi cetakan - tinggi rata-rataa benda uji

$$
=30 \mathrm{~cm}-16,5 \mathrm{~cm}
$$

$=13,5 \mathrm{~cm}$

\subsection{2 umur 14 hari}

Dari pengujian yang telah kami lakukan di laboratorium dinas pekerjaan umum penataan ruang dan perumahan rakyat UPTD pemeliharaan infrastruktur pekerjaan umum wilayah II Kalimantan Timur menghasilkan data, pada sample pertama dengan berat $11,85 \mathrm{~kg}$ dengan bacaan dial sebesar 377,29 kg memiliki kuat tekan sebesar $205,107 \mathrm{~kg} / \mathrm{cm}^{2}$, sample kedua dengan berat $11,80 \mathrm{~kg}$ dengan bacaan dial sebesar $341,6 \mathrm{~kg}$ memiliki kuat tekan sebesar $185,705 \mathrm{~kg} / \mathrm{cm}^{2}$, dan pada sample terakhir dengan berat $11,80 \mathrm{~kg}$ dengan bacaan dial sebesar $392,59 \mathrm{~kg}$ memiliki nilai kuat tekan sebesar $213,422 \mathrm{~kg} / \mathrm{cm}^{2}$. 


\section{2 analisis dampak}

Dampak yang ditimbulkan dari penambahan Arang Sekam Padi ke delam beton ditinjau dari aspek lingkungan, ekonomi, dan sosial.

\subsection{1 aspek lingkungan}

1. Mengurangi pencemaran lingkungan atau mengurangi Arang Sekam Padi sehingga lingkungan sekitar menjadi bersih.

\subsection{2 aspek ekonomi}

1. Harganya yang murah.

\subsection{3 aspek sosial}

1. Pengelolaan limbah yang baik, akan meningkatkan tingkat kesehatan masyarakat.

\section{BAB V}

\section{PENUTUP}

\subsection{Kesimpulan}

1. Hasil uji sesuai SNI $19741990\left(\frac{P}{A}\right.$ X 9,8) dengan nilai P sebesar 1111,49 kgf, ratarata nilai $P$ sebesar $370,5 \mathrm{kgf}$ dan nilai A sebesar $176,786 \mathrm{~cm}^{2}$ didapatkan nilai rata-rata sebesar 380,693 $\mathrm{kg}$ dan menghasilkan mutu beton sebesar 20,531 mpa (14 hari) dan 21,361 mpa (untuk 28 hari).

2. Dengan adanya bahan tambah Arang Sekam Padi ini pada beton kita bisa meningkatkan mutu beton sebesar 2,19 mpa.

\subsection{Saran}

1. Kualitas beton dengan Arang Sekam Padi masih bisa ditingkatkan dengan berbagai metode dan variasi, misalnya penambahan bahan yang harus diganti atau jenis bahan Arang Sekam Padi yang digunkan bisa diubah atau disesuaika 
dengan agregat yang akan digantikan atau bisa juga dengan memvariasikan ukuran Arang Sekam Padi menjadi lebih kecil lagi.

\section{Daftar Pustaka}

[1] A. A. A. Subandi, C. Kusuma, and M. N. Asnan, "Utilization of Ironwood Waste and Husk Charcoal to Produce Lightweight Concrete," International Journal of Civil Engineering, vol. 6, no. 7, pp. 17-22, 2019.

[2] S. N. I. Astm, "Metode uji untuk analisis saringan agregat halus dan agregat kasar ( ASTM C 136-06 , IDT )," 2012.

[3] SNI 1974, "Cara uji kuat tekan beton dengan benda uji silinder," Badan Standardisasi Nasional, 2011.

[4] SNI 03-4810-1998, “Metode Pembuatan dan Perawatan Benda Uji di Lapangan,” pp. $1-8,1998$. 